\title{
Emergência da identidade profissional de professores que ensinam Matemática em conversas numa comunidade virtual de prática
}

Resumo: Este artigo investiga temáticas emergentes sobre a identidade profissional (IP) de professores que ensinam Matemática, a partir de sua participação em uma comunidade virtual de prática (CVP) sediada em um grupo de WhatsApp. Para a produção dos dados foram utilizadas conversas sobre sua formação e a atuação, além dos impactos de sua participação no grupo. Os dados foram analisados tendo a análise de conteúdo como inspiração. Observou-se que três características da IP emergiram nas conversas: a vulnerabilidade, o sentido de agência e o compromisso político. A vulnerabilidade e o sentido de agência se mostraram responsáveis por levar os professores a uma busca por aprendizado permanente sobre a docência. O compromisso político emergiu das narrativas envolvendo sua atuação, já que a busca pela sua melhoria é também entendida como compromisso político com a comunidade. A participação na CVP se mostrou catalisadora da constituição da IP destes professores em uma perspectiva coletiva.

Palavras-chave: Identidade Profissional Docente. Professores que Ensinam Matemática. Comunidade Virtual de Prática.

\section{Emergence of the professional identity of teachers who teach Mathematics in conversations in a virtual community of practice}

Abstract: This manuscript investigates emerging issues about the professional identity (PI) of teachers who teach Mathematics, from their participation in a virtual community of practice (VCP) based on a WhatsApp group. For the data production, conversations about their training and performance were used, as well as the impacts of their participation in the group. The data was analyzed using content analysis. It was observed that three characteristics of the PI emerged in the conversations: vulnerability, sense of agency and political commitment. Vulnerability and a sense of agency were responsible for leading teachers in the search for lifelong learning about teaching. The political commitment arose from the narratives that involve their work, since the search for improvement is also understood as a political commitment to the community. Participation in CVP turned out to be a catalyst for the constitution of the IP of these teachers in a collective perspective. 
Keywords: Teachers' Professional Identity. Teachers who Teach Mathematics. Virtual Community of Practice.

\section{Emergencia de la identidad profesional de profesores que enseñan Matemáticas en conversaciones en una comunidad virtual de práctica}

Resumen: Este artículo investiga temas emergentes sobre la identidad profesional (IP) de docentes que enseñan matemáticas a partir de su participación en una comunidad virtual de práctica (CVP) basada en un grupo de WhatsApp. Para la producción de los datos se utilizaron conversaciones sobre su formación y desempeño, además de los impactos de su participación en el grupo. Los datos se analizaron utilizando el análisis de contenido. Se observó que en las conversaciones surgieron tres características de la IP: vulnerabilidad, sentido de agencia y compromiso político. La vulnerabilidad y el sentido de agencia fueron los responsables de llevar a los docentes en la búsqueda de un aprendizaje permanente sobre la enseñanza. El compromiso político surgió de las narrativas que involucran su trabajo, ya que la búsqueda de mejora también se entiende como un compromiso político con la comunidad. La participación en CVP resultó ser un catalizador para la constitución de la PI de estos profesores en una perspectiva colectiva.

Palabra clave: Identidad Profesional Docente. Profesores que Enseñan Matemáticas. Comunidad Virtual de Práctica.

\section{Introdução}

Uma parcela significativa da população mundial se comunica diariamente por redes sociais virtuais há algumas décadas. Desde 2009, uma das redes mais utilizadas é o WhatsApp, que segundo seu site oficial ${ }^{1}$, foi utilizada por mais de dois bilhões de pessoas, em mais de 180 países, até o fim de 2020.

Dada a facilidade de comunicação entre pessoas, de maneira particular e em grupos, além da variedade de recursos disponibilizados gratuitamente aos usuários, o uso profissional do WhatsApp também passou a ser considerado produtivo por muitas pessoas e organizações. Em particular, professores que ensinam Matemática (PEM) também têm utilizado o WhatsApp, não só para interações pessoais, como também para diferentes formas de interações profissionais entre pares.

Considerando este fato, de que professores têm usado o WhatsApp para interagir sobre questões profissionais, assumimos por hipótese que esse movimento pode impactar suas práticas com suas turmas e na constituição de sua identidade profissional (IP) docente. Portanto, investigar este fenômeno, a partir de conversas com professores que

\footnotetext{
${ }^{1}$ https://www.whatsapp.com/about/
} 
participam de uma comunidade virtual de prática (CVP) no WhatsApp pode trazer contribuições para o campo de pesquisa sobre o desenvolvimento e identidade profissional desse grupo.

Desta forma, nosso interesse neste texto é investigar temáticas emergentes sobre identidade profissional docente a partir de conversas com sete professores que ensinam Matemática na Educação Básica, e que têm em comum a participação, entre dois e cinco anos, em um grupo de WhatsApp destinado a trocas entre PEM sobre o ensino de Matemática, em particular, com foco na colaboração entre pares.

Para isso, fazemos uma breve revisão de literatura sobre identidade profissional docente e comunidades virtuais de prática, sediadas ou não em grupos de WhatsApp. Apresentamos os procedimentos metodológicos da pesquisa para produção de dados conversas com PEM - e análise de dados, inspirada na Análise Temática de Conteúdo. Por fim, as considerações finais.

\section{A identidade profissional docente em comunidades virtuais de prática}

Já há alguns anos, grande parte da população vive o fenômeno da conexão contínua ao ciberespaço por meio de seus smartphones. Nesta conexão, todos os atores envolvidos se influenciam, o ser humano influencia os atores não humanos, seja programando-os diretamente, ou exercendo sua influência na condição de consumidor, na qual programadores e fabricantes modificam programas e estruturas físicas de dispositivos para atender às suas demandas. Neste contexto, também os seres humanos são influenciados pelos atores não humanos, uma vez que a forma como pensamos e agimos se modifica frente aos processos de conexão contínua (SANTAELLA, 2003; BORBA e SOUTO, 2016).

A reunião de pessoas em torno de uma temática em comum é um processo natural (WENGER, McDERMOTT e SNYDER, 2002). Em um contexto hiperconectado, é esperado que esta reunião também se dê na virtualidade. A reunião de PEM em comunidades virtuais de prática é, como a reunião de outros grupos de interesses diversos, um fenômeno da contemporaneidade. Nos dias atuais, pessoas se reúnem com/pelo intermédio da internet de maneira orgânica.

Entendemos, a partir de Santos (2010) e Prevedello (2015), que a reunião virtual de pessoas, em torno de um domínio para a discussão de práticas comuns em comunidade, 
perfaz uma comunidade virtual de prática (CVP) a qual reúne as características fundamentais das comunidades de prática (CoP), ou seja, elas são compostas por "grupos de pessoas que compartilham continuamente uma preocupação, um conjunto de problemas ou uma paixão a respeito de um tópico, e que aprofundam seu conhecimento e experiência em sua área" (WENGER, McDERMOTT e SNYDER, 2002, p. 4). Ainda em relação às CoP, Lima e Borba (2021) afirmam que é o incentivo ao compartilhamento de práticas docentes que faz com que ela seja um ambiente favorável à participação de professores. Consequentemente, entre seus pares, o encorajamento à troca e ao aprimoramento mútuo estabelece um círculo virtuoso em que mais encorajamento implica mais práticas compartilhadas, e quanto mais práticas compartilhadas, mais acolhedor o ambiente fica, o que resulta em mais práticas compartilhadas, mais engajamento, mais apoio recíproco e assim por diante.

Comunidades de prática têm três características fundamentais, segundo Wenger, McDermott e Snyder (2002), a saber, comunidade, domínio e prática. A comunidade pode ser entendida como um grupo de pessoas que tecem conhecimentos conjuntamente, o domínio diz respeito ao assunto que é tema do envolvimento da comunidade e a prática é conhecimento desenvolvido pela comunidade. Tal prática envolve todo o capital cultural desenvolvido pela coletividade envolvida. Cyrino e Caldeira (2011) complementam esta ideia quando acrescentam que a prática de uma comunidade é definida pelos empreendimentos conjuntos de seus participantes.

Em Silva, Esquincalha e Giraldo (2019) apresenta-se um estado do conhecimento sobre CVP em dissertações e teses publicadas no Brasil a partir da década de 2000. Nesse artigo, discute-se, dentre outros temas, as concepções sobre as CVP utilizadas nessas pesquisas pautadas na ideia original de CoP. Para os autores, é possível compreender as CVP como redes nas quais pessoas, que eventualmente nem se conheçam ou atuem em uma mesma instituição, "dedicam tempo e esforços para compartilhar sua expertise e trocar experiências sobre determinado assunto de interesse comum" (SILVA, ESQUINCALHA e GUIRALDO, 2019, p. 6).

Pontuamos também, de acordo com Santos e Santos (2015), que a própria existência de comunidades virtuais de prática é um fenômeno da cibercultura. Portanto, compreender como a tessitura do conhecimento ocorre, mediada por tecnologias digitais 
em rede, nestes novos espaços, é um dos desafios da contemporaneidade, conforme destacado em Silva e Esquincalha (2021). Nesse trabalho, investigou-se a tessitura de conhecimentos em grupos no WhatsApp e observou-se que tal construção se dá em uma perspectiva caótica e ubíqua. Ou seja, tais comunidades constroem conhecimento conjuntamente em uma perspectiva não linear. Frente a este novo paradigma, precisamos repensar estas novas potencialidades comunicacionais e educativas. Uma vez que

a cultura contemporânea, associada às tecnologias digitais, cria uma relação entre a técnica e a vida social. Não podemos compreender os paradoxos, as potencialidades e os conflitos atuais sem a compreensão do fenômeno da cibercultura. [...] É no ciberespaço, e especificamente nos ambientes virtuais de aprendizagem, que saberes são produzidos pela cibercultura, principalmente no que se refere a aprender com o outro, criando uma rede de aprendizagem em um ambiente aberto, plástico, fluido, atemporal e ininterrupto. (SANTOS, e SANTOS, 2015, p. 70)

É um fato que os softwares e suas interfaces fazem parte do nosso dia a dia, modificando a forma como nos relacionamos com o mundo. Nenhuma tecnologia da linguagem e comunicação substitui completamente as que as antecederam, "o que ela faz é alterar as funções sociais realizadas pelas tecnologias precedentes, provocando remanejamentos no papel que cabe a cada uma desempenhar" (SANTAELLA, 2010, p. 18). Portanto, as tecnologias digitais podem ser pensadas como condicionantes de novos comportamentos, dentre eles a organização de comunidades virtuais de prática nas quais possamos trocar e aprofundar conhecimentos. Ou seja, novas relações com o conhecimento, que não destroem as anteriores, mas sim as ressignificam (SANTOS e SANTOS, 2012). Sob essa perspectiva, entendemos que

a dinâmica dos ambientes online é capaz de criar Redes Sociais de docência e aprendizagem, pois permite experiências significativas de aprendizagem nos diferentes espaçostempos da cibercultura, assim, outras e novas redes educativas vão emergindo e inspirando novas práticas cotidianas (SANTOS e SANTOS, 2012, p. 180).

Tais redes sociais de docência e construção de conhecimentos impactam a constituição da identidade profissional (IP) de seus integrantes, uma vez que esta pode ser entendida como resultante de seus processos de tessitura do conhecimento profissional em suas múltiplas dimensões, entre as quais a atuação docente no ciberespaço está incluída, tendo em vista que ela não pode ser dissociada de sua biografia pessoal.

Prática e identidade apresentam aproximações, as quais pontuamos no Quadro 1. 
Quadro 1: Prática e Identidade

\begin{tabular}{|l|l|}
\hline Prática como... & Identidade como... \\
\hline Negociação de significado & Experiência negociada em si \\
\hline Comunidade & Ser membro \\
\hline História e aprendizagem compartilhadas & Trajetória de aprendizagem \\
\hline Limites e cenário & Nexo de multipertencimento a comunidades \\
\hline Constelações & $\begin{array}{l}\text { Pertencimento definido globalmente, mas } \\
\text { vivenciado localmente }\end{array}$ \\
\hline
\end{tabular}

Fonte: Wenger (1998, p. 150, tradução nossa, adaptado)

A IP se constitui em "uma lente através da qual um professor interpreta situações, dá sentido a elas e atua sobre elas" (CYRINO, 2016, p. 6). E, também, que

o movimento de construção/desenvolvimento da IP do PEM se dá tendo vista um conjunto de crenças e concepções interconectadas ao autoconhecimento e aos conhecimentos a respeito de sua profissão, associado à autonomia (vulnerabilidade e sentido de agência) e ao compromisso político (CYRINO, 2016, p. 704).

Quanto às crenças e concepções, segundo Cyrino (2018), o professor que ensina Matemática tem constituído em si mesmo um conjunto de crenças e concepções sobre o que é ser um bom professor de Matemática, sobre o que deve ser ensinado e sobre seu papel enquanto mediador dos processos de ensino e de aprendizagem desta disciplina. Suas crenças estão intimamente imbricadas com o seu conhecimento da própria profissão, quanto ao seu autoconhecimento enquanto ser humano. Quando falamos de autoconhecimento, falamos de autoimagem, autoestima, motivações para o trabalho, percepção de suas tarefas e perspectivas futuras em relação à profissão de professor. Quanto ao conhecimento sobre a profissão, Oliveira e Cyrino (2011, p. 118) afirmam que

o desenvolvimento do conhecimento profissional necessário ao exercício da profissão de professor compreende diversas componentes que, embora nos últimos anos tendo vindo a ser descritas de diversas formas, não se distanciam muito do modelo de Shulman (1986). Assim é consensual que para ensinar Matemática é necessário desenvolver conhecimentos matemáticos e sobre a Matemática, assim como conhecimento sobre como ensinar, nas suas vertentes mais didáctica ou mais pedagógica. No processo de desenvolvimento pessoal do conhecimento profissional estão envolvidas perspectivas e crenças que têm um papel importante não só no modo como o futuro professor aprende mas também em como virá a usar esse conhecimento, desenvolvido num contexto particular da formação inicial, na sua actividade como professor. 
A autonomia do professor é impulsionada pela busca do sentido de agência em situações de vulnerabilidade. Quanto à agência, ela "deixa de ser encarada como uma capacidade ou qualidade individual para ser avaliada como mediada pela interação entre o componente individual (atributos e inclinações) e os artefatos culturais e estruturas do cenário social” (OLIVEIRA e CYRINO, 2011, p. 114).

Já a vulnerabilidade é "um estado fluido de ser, que pode ser influenciado pela forma como as pessoas percebem a situação presente, na medida em que interagem com sua identidade, crenças, valores e senso de competência" (LASKY, 2005, p. 901). O compromisso político na docência pressupõe comprometimento "com os alunos, com os pais, com os colegas de profissão, com a comunidade e, sobretudo, uma responsabilidade social, que envolve as dimensões morais, políticas, emocionais e do conhecimento. É um compromisso de ação e de transformação" (CYRINO, 2017, p. 706).

Tal reunião em uma CVP impacta a identidade de seus participantes e isto não é diferente com PEM. Dentre as diversas oportunidades de temáticas de grupo, em torno das quais orbitam pessoas com os mais diversos interesses, chamam-nos a atenção os PEM que se reúnem na virtualidade para discutir o dia a dia de sua profissão. Estes personagens, portanto, estão no centro da presente pesquisa.

A seguir, apresentamos os procedimentos metodológicos da presente pesquisa.

\section{Procedimentos Metodológicos}

A CVP considerada neste artigo existe desde 2014, caracteriza-se como um grupo de interação e troca espontânea de práticas docentes para e sobre o ensino de Matemática, sediado na rede social WhatsApp. É integrado por 42 professores que ensinam Matemática em instituições públicas e privadas de Educação Básica em diversas regiões do Brasil. Estes professores solicitaram adesão ao grupo voluntariamente, a partir de sua intensa participação anterior em atividades promovidas pela primeira autora deste texto em um grupo de outra rede social, o Facebook, destinado a professores que se interessam pelo ensino de Matemática de forma colaborativa, e que, em abril de 2021, contava com quase 5.000 participantes.

Com o intuito de investigar a emergência de elementos da identidade profissional de PEM nesta CVP, foram convidados sete professores, que estavam no grupo há mais tempo e com maior interação com os demais, para participar individualmente de 
conversas com os autores desse texto, fora do grupo. Todas as conversas foram feitas via internet, uma delas utilizando a ferramenta de vídeo chamada do $\mathrm{Skype}^{2}$, para a professora Raquel; e as demais utilizando a ferramenta de vídeo conferência do Facebook. A gravação de todas as conversas se deu por captura de tela por meio do aplicativo $\mathrm{OCAM}^{3}$. Todos os diálogos foram transcritos em documentos de texto e se constituíram em nosso corpus de análise. Os participantes ${ }^{4}$ da pesquisa aqui relatada são apresentados no Quadro 2.

Quadro 2: Formação e atuação dos participantes da pesquisa

\begin{tabular}{|c|c|c|c|}
\hline Participante & Formação inicial & Pós-Graduação & $\begin{array}{l}\text { Experiência } \\
\text { ensinando } \\
\text { Matemática }\end{array}$ \\
\hline Lauro & $\begin{array}{c}\text { Licenciatura e } \\
\text { Bacharelado em } \\
\text { Matemática (2000) }\end{array}$ & $\begin{array}{c}\text { Especialização em Educação Matemática } \\
\text { (2002) e em Novas Tecnologias no Ensino } \\
\text { (2014). Mestrado Profissional em Educação } \\
\text { em Ciências e Matemática (2019) }\end{array}$ & 13 anos \\
\hline Camila & $\begin{array}{c}\text { Licenciatura em } \\
\text { Matemática (2008) e } \\
\text { em Pedagogia (2010), } \\
\text { Gestão Financeira (em } \\
\text { andamento) }\end{array}$ & $\begin{array}{c}\text { Especialização em Educação Matemática } \\
\text { (2010), em Metodologia da Educação à } \\
\text { Distância (2016) }\end{array}$ & 10 anos \\
\hline Gisela & $\begin{array}{c}\text { Licenciatura e } \\
\text { Bacharelado em } \\
\text { Matemática (2002) }\end{array}$ & $\begin{array}{c}\text { Especialização em Ensino de Matemática } \\
\text { (2007), Mestrado Profissional em } \\
\text { Matemática (2017). Doutorado em } \\
\text { Informática (em andamento) }\end{array}$ & 10 anos \\
\hline Jefferson & $\begin{array}{l}\text { Bacharelado em Física } \\
\text { (2006), Licenciatura } \\
\text { em Física (2015), } \\
\text { Licenciatura em } \\
\text { Matemática (2018) }\end{array}$ & $\begin{array}{c}\text { Mestrado Acadêmico em Física Aplicada às } \\
\text { Ciências Biológicas (2008), Doutorado em } \\
\text { Física Aplicada às Ciências Biológicas } \\
\text { (2013) }\end{array}$ & 4 anos \\
\hline Shila & $\begin{array}{l}\text { Licenciatura em } \\
\text { Matemática (2015) }\end{array}$ & Mestrado Acadêmico em Matemática (2018) & 2 anos \\
\hline Raquel & Licenciatura em & Especialização em gestão e avaliação de & 19 anos \\
\hline
\end{tabular}

\footnotetext{
${ }^{2}$ Programa de compartilhamento de voz e imagem via internet.

${ }^{3}$ Programa gratuito para captura de áudio e vídeo a partir da seleção de uma área na tela do computador no qual ele está instalado.

${ }^{4}$ Nomes modificados para preservar a identidade dos participantes da pesquisa.
} 


\begin{tabular}{|c|c|c|c|}
\hline & Matemática (1998) & $\begin{array}{c}\text { desenvolvimento humano (2007), Mestrado } \\
\text { Acadêmico em Ensino de Matemática } \\
\text { (2017) e Doutorado em Ensino de } \\
\text { Matemática (Em andamento) }\end{array}$ & \\
\hline Ulisses & $\begin{array}{l}\text { Bacharelado em } \\
\text { Engenharia } \\
\text { Metalúrgica (1989), } \\
\text { Licenciatura em } \\
\text { Matemática (2012) }\end{array}$ & $\begin{array}{c}\text { Especialização em Gerenciamento de } \\
\text { projetos (2008), Planejamento, } \\
\text { Implementação, Gestão e Educação a } \\
\text { Distância (2015) e Novas Tecnologias no } \\
\text { Ensino de Matemática (2016) }\end{array}$ & 5 anos \\
\hline
\end{tabular}

Fonte: Dados da Pesquisa

Optamos por utilizar o termo "conversas entre professores", em chamadas de vídeo pelo Messenger do Facebook e pelo Skype como forma de produzir os dados para o presente artigo, tal decisão se deu com base em Alves (2003), que afirma preferir o termo conversa ao termo entrevista, uma vez que o que professores fazem, e gostam de fazê-lo, quando se encontram, é conversar.

Entendemos, com Cyrino (2016), que uma pessoa ao falar de si mesma e de sua atuação no mundo, tanto pessoal quanto profissionalmente, não o faz de forma neutra, mas sim que ela expressa sua visão, valores e entendimento de mundo. Admitimos, nesta pesquisa, portanto, a não neutralidade de nossos sujeitos. Isso não se configura em um problema; mas antes, uma condição do tipo de pesquisa que fazemos. Com Santos, Maddalena e Rossini (2018), sabemos que

a neutralidade, considerada um ponto forte pelos métodos da ciência moderna é descartada, pois somos seres dotados de experiências, vivências, sentimentos que se hibridizam em nossos atos como envolvimento pessoal multidimensional (emocional, sensorial, imaginativo, criativo e racional). Cada uma dessas dimensões deve ser integrada no envolvimento pessoal a partir da implicação dos participantes. Assim, os praticantes culturais implicam-se interativa e recursivamente, com cada um reconhecendo o outro como coautor da pesquisa (p. 97-98)

Ademais, refletir sobre si mesmo, sobre a sua atuação no mundo e sobre as suas relações com o outro envolve o autoconhecimento. Adiante, apresentamos o roteiro (Figura 1) que elaboramos a partir de nossa questão de pesquisa: "Como e quais elementos da IP de PEM emergem na comunidade virtual de prática?", e da nossa revisão de literatura. 


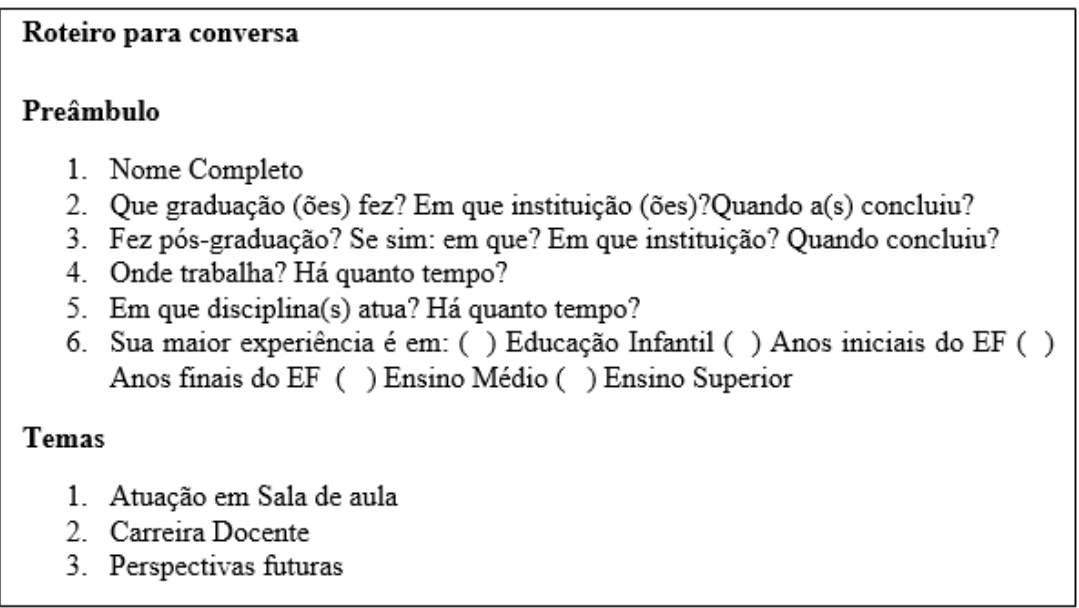

Figura 1: Temas para uma conversa entre professores (Elaboração Nossa).

Para a análise dos dados produzidos, nossa metodologia foi inspirada na técnica de análise temática de conteúdo (RICHARDSON, 2012), a qual se utiliza dos temas e categorias que emergem dos dados para produzir seus resultados. A análise de conteúdo é composta de um conjunto de técnicas de análise de comunicações que visa obter indicadores que permitam as reflexões e conclusões acerca de mensagens a partir da sua produção e recepção, por meio de procedimentos sistemáticos e objetivos da descrição do conteúdo delas.

Esta análise consiste no isolamento de temas de um texto e extração de suas partes utilizáveis, de acordo com o problema pesquisado, com o objetivo de viabilizar a sua comparação com outros textos escolhidos da mesma maneira. Para tanto, são escolhidos dois tipos de tema: principais e secundários. O primeiro permite a definição do conteúdo da parte analisada de um texto e o segundo permite a especificação de diversos aspectos presentes no primeiro.

A análise temática de conteúdo é uma das mais antigas e utilizadas dentre as diferentes correntes da análise de conteúdo, as quais não detalharemos aqui por fugir ao escopo do presente trabalho. Para o presente estudo, por uma questão de foco, limitamonos a apresentar suas características metodológicas, a saber: objetividade (explicitação de regras e procedimentos utilizados para cada etapa da análise); sistematização (inclusão ou exclusão do conteúdo ou categorias de um texto de acordo com regras consistentes e sistemáticas) e inferência (saída da descrição e chegada à interpretação dos dados) e a descrever de que maneira sua utilização foi feita na pesquisa (RICHARDSON, 2012).

Considerando a metodologia e o corpus de pesquisa em questão, efetuamos: a) 
uma análise do material, que consistiu em sua leitura exaustiva; b) uma categorização, que se baseou no tratamento dos resultados, na inferência e na interpretação deles. Fizemos uma leitura cuidadosa do corpus, na qual buscamos perceber indícios de construção coletiva de conhecimento e elementos de constituição de identidade profissional docente. No próximo item, apresentamos a análise dos dados produzidos.

\section{Análise dos dados}

Por meio da leitura exaustiva do corpus, na perspectiva da análise temática de conteúdo, observamos o emergir de quatro temáticas, a saber: busca por formação; Matemática além das contas; busca de pares; troca de práticas em grupo. Apresentamolas e discutimo-las adiante.

\subsection{Busca por formação}

Observamos o reconhecimento, por parte de cada um dos participantes, de que a sua formação é um processo contínuo. Tal preocupação emergiu em cada conversa que tivemos e se materializou nos títulos acadêmicos obtidos pelos integrantes, uma vez que dentre os sujeitos desta pesquisa temos seis mestres (dois deles estudantes de doutorado), um doutor e dois especialistas (um deles estudante de mestrado). Continuar estudando, com vistas a melhorar continuamente a própria prática enquanto PEM, foi observado como uma unanimidade entre todos os ouvidos. Destacamos abaixo algumas falas que representam esta temática.

[...] E aí, eu cheguei a fazer a pós, foi logo em seguida de terminar a graduação. Aprendi algumas coisas, e sempre tentava fazer em sala. Tipo, eu lembro muito bem de uma atividade que é Matemática ligada com educação física, trabalhando com o Índice de Massa Corporal. E achei até legal porque aí eu coloquei os alunos para medirem os colegas... Algo que fazia sentido para eles. Eles estavam fazendo um cálculo que era para eles. E até mesmo para trabalhar com os números, né... racionais e inteiros. Então, foi algo que eu acabei aprendendo na pós. (Lauro)

Eu era uma pessoa extremamente conteudista, então eu acreditava na Matemática pela Matemática, mas aos poucos meus alunos me ensinaram que não era bem por aí, porque para ensinar, a Matemática era necessária, mas não suficiente... E foi então que eu fui buscar especializações que visassem principalmente a área de relações humanas, por isso avaliação, desenvolvimento humano e gestão foram minhas primeiras especializações. (Raquel)

A minha perspectiva é no maior ato de resistência de continuar estudando, continuar colocando em prática e compartilhando com os colegas e aprendendo o tempo todo. Se eu entender que eu preciso aprender o tempo todo, talvez meus alunos vejam isso também e isso seja bom para eles. (Raquel) 
A busca por formação, que transborda das falas dos PEM com quem conversamos, mostra-nos as suas percepções a respeito da sua profissão, o seu autoconhecimento enquanto professores e sua consciência quanto aos seus conhecimentos profissionais. Em nosso entendimento, é o conjunto destas percepções que impulsiona a vulnerabilidade destes professores, ou seja, é a percepção de que é necessário saber mais para melhor desempenhar o seu papel profissional.

E, quando falamos de vulnerabilidade, não estamos nos referindo à fraqueza de natureza alguma, mas concordando com Oliveira e Cyrino (2011) no entendimento de que a "vulnerabilidade encarada em qualquer momento da carreira docente, enquanto condição estruturante da profissão, pode constituir uma experiência de abertura e confiança fundamentais à construção de conhecimentos do professor" (p. 114). Além disso, a partir dos trechos apresentados, é possível articular a vulnerabilidade como propulsor do desenvolvimento profissional, associando ao conceito de agência.

Ambas as falas de Lauro e Raquel mostram o reconhecimento da importância de buscar formação para além da graduação para lidar melhor com desafios que enfrentavam como professores que ensinam Matemática. Emergem aqui o autoconhecimento e o conhecimento profissional matemático e pedagógico para superar este obstáculo. Além dessa formação institucionalizada, percebe-se a busca pela formação por meio da troca com pares, com sua participação em grupos em redes sociais que reúnem professores que ensinam Matemática, como na CVP. Silva e Esquincalha (2021, p. 20) destacam que esses grupos dão suporte a recursos hiper midiáticos, além de ensejarem "situações ubíquas de tessituras do conhecimento" por meio das interações que podem ocorrer a todo momento entre docentes participantes, ressignificando seu uso social para uma ambiência formativa.

Retomando a ideia da vulnerabilidade e sentido de agência, percebidos nas falas apresentadas, Oliveira e Cyrino (2011) afirmam que têm íntima ligação com a atividade profissional de ensinar Matemática, pois

para ensinar Matemática é necessário desenvolver conhecimentos matemáticos e sobre a Matemática, assim como conhecimento sobre como ensinar, nas suas vertentes mais didáctica ou mais pedagógica. No processo de desenvolvimento pessoal do conhecimento profissional estão envolvidas perspectivas e crenças que têm um papel importante não só no modo como o futuro professor aprende mas também em como virá a usar esse conhecimento, desenvolvido num 
contexto particular da formação inicial, na sua actividade como professor. (OLIVEIRA e CYRINO, 2011, p. 118)

A reação de ambos, Lauro e Raquel, frente a esta percepção, foi a mesma, ou seja, a busca por mais conhecimento para sua prática profissional. Tal busca é explicitada em trechos de suas falas, tanto quando Lauro afirma: "E aí, eu cheguei a fazer a pós, foi logo em seguida de terminar a graduação; aprendi algumas coisas, e sempre tentava fazer em sala", como quando Raquel diz: "e foi então que eu fui buscar especializações que visassem principalmente à área de relações humanas, por isso avaliação, desenvolvimento humano e gestão foram minhas primeiras especializações".

Observamos tal busca como o reconhecimento da vulnerabilidade e entendemos que ela impacta diretamente na IP dos professores, uma vez que o seu desenvolvimento remete a um complexo processo que envolve "aspectos pessoais, profissionais, intelectuais, morais e políticos dos grupos nos quais os sujeitos estão envolvidos. [...] Não consiste apenas no que os outros pensam ou dizem de nós, mas de como nos vemos e da capacidade de refletirmos sobre a nossa experiência” (CYRINO, 2016, p. 168).

Portanto, a vulnerabilidade à qual nos referimos contempla a consciência dos PEM com quem dialogamos quanto à necessidade contínua de tessitura plural do conhecimento frente aos desafios trazidos pela docência. Desafios aos quais eles respondem por meio da busca de formação, não só em cursos formais, mas também formação dentro do contexto da própria profissão, ao unir a teoria à prática, além da formação e por meio da troca entre pares em diferentes ambientes formativos.

Vemos também aqui a agência em ação, visto que ela "deve ser entendida como a conjugação de esforços individuais, recursos disponíveis e 'factores' contextuais e estruturais [...] em situações, de certa forma, únicas" (OLIVEIRA e CYRINO, 2011, p. 115).

No próximo item, dedicamo-nos à análise da segunda temática emergente de nosso corpus, a transcendência de um ensino de Matemática centrado em livros e fórmulas.

\subsection{Matemática além das contas}

A preocupação com um aprendizado de Matemática muito além da repetição de fórmulas e contas, e de uma ânsia de contribuir para os processos de ensino e de 
aprendizagem de seus alunos para além do livro didático emergiu em nossa análise. Observamos aqui que as percepções dos PEM com quem conversamos sobre o ensino de Matemática e que o conhecimento profissional destes a esse respeito, assim como o seu compromisso político com a profissão, transparecem em suas colocações. Tal transparência pode ser observada nas falas que, adiante, elencamos.

Eu gosto de levar os alunos a pensarem, a sonharem, a buscarem algo que por vezes eles... Parece que eles vivem num mundo, num dia a dia tão "comer, beber, dormir", sem pensar o que pode ser o amanhã na vida deles. Então eu tenho essa preocupação. (Ulisses)

Eu ainda acho que existe um desafio muito grande em dar uma Matemática que seja uma ferramenta pra justiça social, então para que, de fato, os meninos consigam usar a Matemática pra olhar o mundo, interpretar o mundo e atuar no mundo. (Jefferson)

Eu sempre tento sair um pouco do tradicional, né. Eu fui um aluno no fundamental e no médio que via a Matemática apenas como um cálculo, não via aplicações, não via outras metodologias a não ser quadro e giz. E aí quando eu comecei a ensinar, devido a universidade que também me deu um suporte muito bom por ter participado quase cinco anos do PIBID, eu comecei a utilizar outros artifícios, outros recursos dentro da sala de aula, então crio jogos, pego alguns prontos, faço adaptações que se adequam à realidade da turma; utilizo algumas vezes tecnologia, celular, que é mais fácil de utilizar com os alunos porque a maioria tem, já que a escola não tem computadores... (Shila)

[...] então, faço sempre coisas novas pra ver se eu deixo essa Matemática mais divertida pra eles, mais atrativa. (Camilla)

A minha atuação parte do princípio de que eu preciso do engajamento do aluno. Nós temos desenvolvido estratégias, né, para engajar o nosso aluno e a partir disso proporcionar o aprendizado, o ambiente né de investigação então a partir disso é... Nós esperamos que eles efetivamente aprendam. (Gisela)

[...] Com o passar do tempo eu vejo que o aluno aprende muito pouco seguindo as coisas que estão no livro didático, os exercícios que são colocados. E a gente também começa a questionar. Que a resolução do exercício que está no livro didático do professor às vezes o aluno não compreende e às vezes até a gente mesmo não compreende a resolução porque ela também não é colocada passo a passo e muitas vezes não segue uma ordem... Aí você começa a questionar. Pô, o que eu tô fazendo ali? Tô dando aula para o aluno aprender, mas o meu aluno não está aprendendo e muitas vezes é a gente também que não está aprendendo nada. (Lauro)

Apoiados em Wenger, McDermott e Snyder (2002), vemos aqui um interesse compartilhado, o qual, na literatura acerca das $\mathrm{CoP}$, entendemos como sendo um domínio. $\mathrm{O}$ domínio, quando unido à prática e à comunidade, perfaz uma CoP. Nesta temática, emerge a necessidade dos PEM em foco de transcender um ensino centrado nos objetos matemáticos e em buscar a construção do conhecimento do aluno.

Em sua fala, a professora Shila expressa tanto esta necessidade de transcendência, quanto o uso do ciberespaço para alcançá-la, quando comenta que utiliza diferentes 
recursos em suas aulas, incluindo os tecnológicos que podem ser explorados por telefones celulares. Também identificamos na fala dos professores Ulisses e Jefferson a preocupação com uma educação matemática crítica, voltada para a justiça social. Na literatura sobre IP docente na qual, nos fundamentamos, isso é caracterizado como compromisso político, como vemos em Cyrino (2017):

\begin{abstract}
O trabalho com as crenças e as concepções associado ao autoconhecimento profissional pode contribuir para o desenvolvimento da autonomia e do compromisso político do futuro professor. A ação docente não está relacionada somente a valores e normas educacionais, mas também a conhecimentos e crenças individuais dos professores. Existem relações políticas, nem sempre explícitas, que permeiam a relação do professor com o aluno, com o contexto escolar, com a organização educativa e com as políticas públicas educacionais, com os quais os professores precisam lidar. (p. 705).
\end{abstract}

Tal compromisso emerge tanto de nossa conversa com Ulisses, quanto de nossa conversa com Jefferson, quando eles expressam suas preocupações no sentido de fazer com que a sala de aula seja espaço de transformação social quando afirmam que: "Eu gosto de levar os alunos a pensarem, a sonharem, a buscarem algo [...]" (Ulisses) e "Eu ainda acho que existe um desafio muito grande em dar uma Matemática que seja uma ferramenta pra justiça social" (Jefferson).

Segundo Oliveira e Cyrino (2011), o ato de aprender traz transformação pessoal, e é esta transformação que permeia todas as falas destacadas, seja envolvendo a Matemática como meio para o estímulo à busca de perspectivas para transformação social e como a afirmação de um compromisso político, como na fala dos professores Ulisses e Jefferson; seja na busca do seu aprendizado por meio de atividades diferenciadas, como na fala das professoras Camila e Gisela, ou seja, na problematização de que Matemática se ensina e do porquê de os estudantes não a aprenderem, como na fala do professor Lauro.

No próximo item, dedicamo-nos à análise da terceira temática emergente de nosso corpus, a qual trata da necessidade da busca de professores de Matemática com interesses em comum.

\title{
4.3 Busca de pares
}

A busca da superação da solidão docente se destacou nas conversas que tivemos. Nelas, encontramos uma busca recorrente por pares com quem se pudesse discutir o dia 
a dia da docência em Matemática na Educação Básica. Observamos, a partir das colocações dos professores em foco, que elementos de sua IP como o autoconhecimento, o conhecimento profissional e o compromisso político os impulsionam à vulnerabilidade e ao sentido de agência. As falas que se destacaram nesta temática estão transcritas adiante.

\begin{abstract}
Aí a gente conheceu a prática do professor Fabiano ${ }^{5}$ e eu disse: caraca! Um professor da rede igual, com o mesmo interesse que eu, está fazendo coisas novas! Novidade! Muito interessante! Que é aplicável na minha sala de aula! A foto da época mostra o quanto eu fiquei com os olhinhos brilhando assim. Muito legal, muito legal! Os alunos são iguaizinhos aos meus! Mesma realidade, né? Mesmo enfrentamento de alegrias e tristezas! [...] E foi assim que acabei conhecendo e passei a seguir direto nas redes sociais. (Lauro)
\end{abstract}

Acho que quando eu fui pro grupo do WhatsApp, um pouco do que eu tava procurando era isso, eram outras pessoas pra discutir. Ah, acho que às vezes, além da solidão, é difícil... Apesar da solidão e de ser muito prioritário é... Na minha vida achar outras pessoas pra discutir, a vida atropela a gente e mesmo assim é muito difícil montar esses grupos porque às vezes não sou eu, é outra pessoa que não tem tempo sabe? Mas estar no grupo e poder postar a qualquer hora é muito bom, são muitos colegas, alguém sempre responde, anima a gente... nem que seja de madrugada, fim de semana... (Jefferson).

O que me estimula a estar com vocês é aprender a andar com pessoas que nos desafiam, e quando andamos com pessoas que nos desafiam, nós crescemos. É o poder de estar em grupo! (Ulisses)

É tipo, você estar dentro de um grupo que tem professores da educação básica, de escola pública que faz um diferencial. Eu acho que já agrega bastante valor a você se encorajar e fazer o mesmo. Às vezes a gente fica desestimulado, mas aí a gente vê como tem pessoas que têm o mesmo o cargo, até com dificuldades maiores e conseguem, e aí você é encorajado a fazer. (Shila)

O rompimento deste isolamento e a reunião docente em comunidade são facilitados pela cibercultura, como pontuam Santos e Santos (2012):

\begin{abstract}
Muitos professores estão na internet partilhando esses usos como membros nas Redes Sociais. Embora seja muitas vezes uma expressão individual de um ou outro professor, essas práticas refletem a necessidade que eles sentem de ressignificar suas aulas e seus conteúdos, tornando-os interessantes e significativos, a partir dos recursos digitais viabilizados pela internet, conjugando o cenário sociotécnico e as redes educativas dentrofora da escola. Percebemos [...] o potencial dessas mídias e redes sociais como estruturantes de novas formas de pensamento, como instrumentos culturais de aprendizagem, mediando novos processos tecnológicos, comunicacionais e pedagógicos (p. 180).
\end{abstract}

Nesta direção, Figueiredo, Costa e Llinares (2021) destacam que os

\footnotetext{
${ }^{5}$ Alterado para preservar a identidade dos participantes da CVP considerada.
} 
conhecimentos tecnológicos, em si, não fazem com que o desenvolvimento e a competência profissional de professores sejam desenvolvidos. Para este profissional, mais do que ser usuário de tecnologia, é necessário pensar pedagogicamente como esta tecnologia pode ser útil na construção do aprendizado de seus alunos. Este pensar pedagógico, para os autores supracitados, é favorecido pelo encontro, pela coletividade.

O encontro e a possibilidade de reunião para troca de ideias sobre o ensino de Matemática com outros professores animaram os PEM com quem conversamos. Jefferson, por exemplo, enuncia literalmente esta necessidade e materializa sua vulnerabilidade e agência quando afirma: "Acho que quando eu fui pro grupo do laboratório de Matemática [...] um pouco do que eu tava procurando era isso, eram outras pessoas pra discutir [...]".

Das falas dos professores emerge um interesse de reunião com colegas que busquem a melhoria constante de suas aulas, o que se identifica com as percepções dos integrantes da comunidade sobre o que é ser um bom professor de Matemática. Neste caso, alguém que busque e vivencie formas diferenciadas para os processos de ensino e de aprendizagem de Matemática, buscando constantemente ser o melhor professor possível no seu contexto de atuação.

A ubiquidade discutida por Silva e Esquincalha (2021) é destacada por Jefferson e aparece também, implicitamente, nas falas de outros professores. A possibilidade de onipresença virtual possibilitada pelo WhatsApp e outras redes sociais pode fomentar uma ambiência formativa permanente, de modo que quase sempre haverá alguém disposto a trocar e amparar o colega sempre que necessário, seja compartilhando práticas e reflexões sobre a docência em Matemática, ou seja oferecendo uma palavra de ânimo.

As pessoas, membros de uma CVP, não necessariamente têm o mesmo ponto de vista, ou defendem as mesmas formas de ensino, mas sentem a urgência de melhorar as suas aulas e veem, na interação com colegas com as mesmas aspirações, a possibilidade de fazê-lo conjuntamente, sem constrangimentos. Vemos, portanto, nesta busca, a vulnerabilidade que impulsiona a agência mediada presente nas pesquisas de Cyrino (2016, 2017, 2018) e Oliveira e Cyrino (2011).

Entendemos, com Cyrino (2018, p. 13), que, para a construção coletiva na qual a discussão entre PEM possa se dar de forma livre e proveitosa, é necessário que se 
estabeleça um ambiente seguro no qual cada professor se sinta livre para se expressar, pois "a construção colaborativa de uma agência mediada é fundamental para que os professores tenham um ambiente seguro e o apoio de que necessitam para se sentirem suficientemente capacitados para assumir riscos e praticar a vulnerabilidade experiências essenciais para o desenvolvimento da identidade”. E que tal desiderato, quando alcançado coletivamente, pode impactar na constituição da IP dos PEM participantes de tal ambiente.

Na próxima seção, dedicamo-nos à análise da quarta temática emergente de nosso corpus, a qual trata da troca de práticas em grupo.

\subsection{Compartilhamento de práticas em grupo}

Vimos aqui que os professores com quem conversamos ressaltam a importância da troca de práticas Matemáticas para o ensino, que ocorre entre os participantes da comunidade; também mencionam o fato de que os professores participantes se sentem à vontade para partilhar propostas, uma vez que eles se identificam com o viés da discussão na CVP aqui considerada. As práticas que os PEM buscam compartilhar dizem muito a respeito de sua IP, falam de suas percepções acerca do ensino de Matemática, do seu autoconhecimento e do seu conhecimento profissional. Destacamos adiante algumas falas que representam esta percepção de nossos PEM.

Hoje a gente conta com muita gente compartilhando suas práticas sem medo de ser feliz, sem medo de dizer que não sabe, sem medo de errar, sem medo de ser visto com a autoestima baixa, porque estamos entre pares e isso é muito importante, e foi assim que eu cheguei ao grupo do WhatsApp. (Raquel)

Eu gosto muito dos trabalhos que o pessoal divulga no grupo, sabe? Do trabalho que eles estão fazendo, muitos eu já vou baixando e vou guardando. Teve um jogo que vocês mandaram esses dias, eu guardo todo esse material e conforme eu vou tendo a necessidade, eu vou usando em sala de aula. Ou até mesmo eu vou pegando algum do que vocês mostram lá “ah não é da minha faixa etária ali”, eu adapto pros meus alunos. (Camila)

Estando no grupo eu realmente vi que era aquilo lá mesmo que eu tinha a expectativa. Era uma coisa que eu posso colaborar mesmo não estando aí no Rio, vocês colaboram com a minha prática aqui, e está tendo essa colaboração mesmo. (Camila)

Letícia ${ }^{6}$ e eu já tínhamos desenvolvido vários trabalhos né, com mais dois amigos. Trabalhos nessa perspectiva de transformar a nossa sala de aula, de fazer com que os nossos alunos tenham engajamento. Então foi um convite da Letícia, né, foi ela que primeiro conheceu o grupo de vocês e me procurou, falou "Gisela, a galera lá tá

\footnotetext{
${ }^{6}$ Letícia e Gisela fizeram o Mestrado juntas, Letícia também é membro da CVP.
} 
buscando inovação, tá buscando transformar a sua sala de aula igual à gente. Acho que a gente vai agregar e vai aprender muito com eles." Eu aprendo muito com todos do grupo. (Gisela)

Fazendo uma avaliação de mim mesma, quando eu estava na graduação, mesmo trabalhando como professora. Quando eu estava na graduação eu era bem mais produtiva em relação à criação de jogos, a aplicação de outras metodologias. Depois que eu entrei no meu mestrado, e aí eu passei pra uma outra área, apesar de que eu gosto das duas... Mas aí no mestrado me decidi pela Matemática pura, eu meio que parei um pouco em relação à educação da Matemática. Assim, quando eu vejo vocês produzindo isso me motiva também a produzir, a levar algo de diferente pra a sala de aula. (Shila)

Uma comunidade de prática é um lugar no qual as pessoas têm liberdade para ajudar e serem ajudadas. Isto ocorre, pois a comunidade é, segundo Wenger, McDermott e Snyder (2002, p. 61), "como um bar ou café da vizinhança, a comunidade se torna um 'lugar' onde as pessoas têm a liberdade de pedir conselhos sinceros, compartilhar suas opiniões e experimentar suas ideias". Ou seja, "são lugares que as pessoas podem visitar para ouvir sobre a última ferramenta, trocar fofocas, técnicas ou apenas conversar sobre questões técnicas sem medo de se comprometer com planos de ação" (WENGER, MCDERMOTT e SNYDER, 2002, p. 61). Nas falas selecionadas dos professores, vemos que a CVP é este lugar de reunião para compartilhamento de práticas. Um lugar seguro, no qual é possível se expor, e mais do que isso, expor fraquezas e dúvidas a um coletivo que irá propor ações positivas e contribuir coletivamente para sanar as necessidades dos seus indivíduos.

Podemos observar este desassombro em um trecho da professora Raquel, quando ela afirma que: "Hoje, a gente conta com muita gente compartilhando suas práticas sem medo de ser feliz, sem medo de dizer que não sabe, sem medo de errar, sem medo de ser visto com a autoestima baixa porque estamos entre pares e isso é muito importante". Dessa fala transparece a vulnerabilidade, uma vulnerabilidade que permite a abertura à opinião do outro em um ambiente no qual os participantes aparentemente se sentem seguros. A professora Camila também expressa esta liberdade que sente para colaborar com o grupo e a importância da colaboração do grupo com a sua própria prática, ela ainda destaca a vantagem de poder fazê-lo na virtualidade.

Também é possível observar o entendimento, por parte de participantes, da comunidade como sendo um local no qual se aprende e se ensina, retomamos aqui as falas de Gisela, que observa esta construção do conhecimento em uma via de mão dupla, quando enuncia que: “A galera lá tá buscando inovação, tá buscando transformar a sua 
sala de aula igual à gente. Acho que a gente vai agregar e vai aprender muito com eles. Eu aprendo muito com todos do grupo". E de Shila, que observa uma mão única: “Assim, quando eu vejo vocês produzindo, isso me motiva também a produzir, a levar algo de diferente pra sala de aula".

Vemos aqui a agência em ação, uma vez que "a agência é sempre mediada pela interacção entre a componente individual (atributos e inclinações) e as ferramentas e estruturas do cenário social” (LASKY, 2005, p. 900), daí que faça sentido falar de uma "agência mediada" (OLIVEIRA e CYRINO, 2011, p. 114). Desta maneira, podemos afirmar, a partir das falas elencadas, que a agência que aqui emerge o faz na interação com o outro.

\section{Considerações finais}

Nosso objetivo com o presente artigo foi o de investigar, a partir de conversas com sete professores que ensinam Matemática em diferentes regiões do país, e que se reúnem há alguns anos em uma comunidade virtual de prática sobre ensino colaborativo de Matemática, que elementos de sua identidade profissional docente emergem a partir de sua participação nessa comunidade, sediada em um grupo de WhatsApp.

A identidade pessoal está intimamente imbricada na identidade profissional de qualquer pessoa. Quem somos, onde estamos, como percebemos e nos colocamos para o mundo, assim como os contextos nos quais nos inserimos e as relações que travamos neles estão amalgamadas no profissional que somos. Posto que, como membros de uma comunidade sociocultural, nela atuamos em diferentes papéis.

A interação dos participantes da pesquisa na CVP se dá a partir das necessidades de seus integrantes. Necessidades estas que partem de seu compromisso político, de suas percepções, do seu autoconhecimento, do seu conhecimento profissional, os quais impulsionam a vulnerabilidade e a busca do sentido de agência dos integrantes da comunidade em foco. Nela, tal interesse é a necessidade do encontro com outros professores que ensinam Matemática e que buscam romper o isolamento da sala de aula - desta necessidade se mantém a comunidade - e trocar práticas com pares a fim de melhorar a própria atuação como professor que ensina Matemática — desta necessidade, nasce a prática dentro de um domínio -, o que contempla os três elementos fundantes de 
uma comunidade de prática, como supracitados: comunidade, domínio e prática.

Observamos que duas características da identidade profissional docente se sobressaíram dos dados produzidos, a saber, a vulnerabilidade e o sentido de agência. A vulnerabilidade e o sentido de agência se mostraram como os motores responsáveis por levar os professores investigados a uma busca por um aprendizado permanente envolvendo a docência (transcendendo limitações, ampliando o entendimento sobre como melhor promover a tessitura do conhecimento matemático, aprendendo novas habilidades), tanto em um sentido formal (por meio de cursos chancelados por universidades), quanto informalmente (em pesquisas na internet e por meio da interação com pares).

Ambas as características são impulsionadas ora pelas percepções, ora pelo conhecimento profissional e ora pelo autoconhecimento dos professores que ensinam Matemática com quem conversamos. O que se mostrou continuamente presente foi o seu compromisso político com a profissão, com seus alunos e com seus pares. Ele emergiu das narrativas envolvendo a sua atuação docente, uma vez que a busca permanente por aprendizado, visando a melhoria contínua de suas atuações enquanto professores que ensinam Matemática, é também entendido aqui como compromisso político com os estudantes e com a comunidade.

Portanto, participar na CVP considerada neste trabalho impacta a identidade profissional dos participantes consultados na interação com o outro, e um outro que é espelho, um outro que é um par. Ou seja, com pares que compartilham: uma busca permanente por aprendizagem; um desejo de transcender um ensino de Matemática livresco, formulístico, sem reflexão; uma vontade de se encontrar para conversar, trocar ideias, apoiar e ser apoiado. Aqui estamos falando de uma identidade profissional que é construída em nós, e que passa também pelo(s) outro(s). Conexões entre professores que ensinam Matemática no ciberespaço interferem na constituição de sua identidade profissional.

Este estudo contribui para o campo de pesquisa analisando como elementos desta IP emergem em interações no ciberespaço. Como desdobramentos futuros da presente pesquisa, pretendemos pesquisar a forma como os professores participantes desta pesquisa desenvolvem o ensino de Matemática com seus estudantes em suas salas de aula. 
Fechamos este artigo com uma frase de um autor desconhecido e que reflete o que aqui discutimos. "Nenhum de nós é tão bom quanto todos nós juntos".

\section{Referências}

ALVES, Nilda. Cultura e cotidiano escolar. Revista Brasileira de Educação, Rio de Janeiro, n. 23, p. 62-74, ago. 2003.

BORBA, Marcelo de Carvalho; SOUTO, Daise Lago Pereira. Seres Humanos-ComInternet ou Internet-Com Seres Humanos: uma troca de papéis? Relime, Ciudad de México, v. 19, n. 2, jan. 2016.

CYRINO, Márcia Cristina de Costa Trindade. Grupos de estudo e pesquisa e o movimento de constituição da identidade profissional de professores que ensinam Matemática e de investigadores. REnCiMa, São Paulo, v. 9, n. 6, p. 1-17, 2018.

CYRINO, Márcia Cristina de Costa Trindade. Identidade profissional de (futuros) professores que ensinam Matemática. Perspectivas da Educação Matemática, Campo Grande, v. 10, n. 24, p. 699-712, set./dez. 2017.

CYRINO, Márcia Cristina de Costa Trindade. Mathematics teachers' professional identity development in communities of practice: reifications of proportional reasoning teaching. Bolema, Rio Claro, v. 30, n. 54, p. 165-187, abr. 2016.

CYRINO, Márcia Cristina de Costa Trindade; CALDEIRA, Janaina Soler. Processos de negociação de significados sobre pensamento algébrico em uma Comunidade de Prática de formação inicial de professores de Matemática. Investigações em Ensino de Ciências, Porto Alegre, v. 16, n. 3, p. 373-401, dez. 2011.

FIGUEIREDO, Sonner Arfux de; COSTA, Nielce Meneguelo Lobo da; LLINARES, Salvador. Olhar profissional para a docência com tecnologia: um estudo na formação continuada. Educação Matemática Debate, Montes Claros, v. 5, n. 11, p. 1-23, 28 jan. 2021.

LASKY, Sue. A sociocultural approach to understanding teacher identity, agency and professional vulnerability in a context of secondary school reform. Teaching and Teacher Education, v. 21, n. 8, p. 899-916, 2005.

LIMA, Ana Paula Barbosa de; BORBA, Rute Elizabete de Souza Rosa. Comunidades de Prática e a formação do professor que ensina Matemática revisitando teses e dissertações. Educação Matemática Debate, Montes Claros, v. 5, n. 11, p. 1-30, jan. 2021.

OLIVEIRA, Hélia Margarida; CYRINO, Márcia Cristina de Costa Trindade. A formação inicial de professores de Matemática em Portugal e no Brasil: narrativas de vulnerabilidade e agência. Interacções, Santarém, v. 7, n. 18, p. 104-130, 2011.

PREVEDELLO, Clarissa Felkl. Comunidades virtuais de prática no serviço público: quadro teórico para a organização de experiências e apoio à inovação. 2015. 222f. Tese (Doutorado em Informática na Educação) - Centro de Estudos Interdisciplinares em 
Novas Tecnologias da Educação. Universidade Federal do Rio Grande do Sul. Porto Alegre.

RICHARDSON, Roberto Jarry. Pesquisa Social: métodos e técnicas. São Paulo: Atlas, 2012.

SANTAELLA, Lúcia. A aprendizagem ubíqua substitui a educação formal? Revista de Computação e Tecnologia, São Paulo, v. 2, n. 1, p. 17-22, out. 2010.

SANTAELLA, Lúcia. Da cultura das mídias à Cibercultura: o advento do pós humano. Revista Famecos, Porto Alegre, v. 10, n. 22, p. 23-32, dez. 2003.

SANTOS, Edméa; MADDALENA, Tania Lucia, ROSSINI, Tatiana. Diário hipertextual online de pesquisa: uma experiência com o aplicativo Evernote. In: SANTOS, Edméa, CAPUTO, Stela Guedes. (Org.). Diário de pesquisa na Cibercultura: narrativas multirreferenciais com os cotidianos. Rio de Janeiro: Omodê, 2018, p. 91-110.

SANTOS, Fladimir Fernandes dos. Modelo de gestão para promover a criação e o compartilhamento de conhecimento em Comunidade Virtual de Prática. 2010. 244f. Tese (Doutorado em Engenharia e Gestão do Conhecimento) - Centro Tecnológico, Universidade Federal de Santa Catarina. Florianópolis.

SANTOS, Rosangela; SANTOS, Edméa Oliveira. Cibercultura: redes educativas e práticas cotidianas. Revista Eletrônica Pesquiseduca, Santos, v. 4, n. 7, p. 159-183, jan./jul.2012.

SANTOS, Rosemary. SANTOS, Edméa. Pesquisando nos cotidianos da Cibercultura: uma experiência de pesquisa-formação multirreferencial. Revista da FAEEBA: Educação e Contemporaneidade, Salvador, v. 24, n. 44, p. 69-82, jul./dez. 2015.

SILVA, Daniela Mendes Vieira; ESQUINCALHA, Agnaldo da Conceição. A tessitura do conhecimento em grupos de WhatsApp. Revista Brasileira de Aprendizagem Aberta e a Distância, São Paulo, v. 20, n. 1, p. 1-27, mar. 2021.

SILVA, Daniela Mendes Vieira; ESQUINCALHA, Agnaldo da Conceição; GIRALDO, Victor Augusto. Estado do conhecimento sobre comunidades virtuais de prática em dissertações e teses brasileiras. EaD em Foco, Rio de Janeiro, v. 9, n. 1, p. 1-12, mai. 2019.

WENGER, Etienne. Communities of Practice: learning, meaning and identity. New York: Cambridge, 1998.

WENGER, Etienne; McDERMOTT, Richard; SNYDER, William. Cultivating Communities of Practice: a guide to mananging knowledge. Boston: Harvard Business School Publishing. 2002. 